\section{Cash boost for mapping the human brain}

The US National Institutes of Health last week launched an initiative to map the wiring of the human brain. The Human Connectome Project will provide $\$ 30$ million over five years for work detailing the connections between major brain subdivisions in healthy adults.

Neuroscientists increasingly view the human connectome as crucial to understanding mental function and disease (see Nature 457, 524-527; 2009). The project demonstrates commitment to this nascent research field, and will generate "a new class of data for human neuroscientists", says its leader Michael Huerta of the National Institute of Mental Health.

Researchers will try to link brain connectivity to genetics and behaviour, by collecting DNA samples, demographic information and behavioural data from their subjects. The initiative also aims to improve non-invasive brain-imaging technologies.

\section{ExxonMobil invests in algae for biofuel}

Oil and gas company ExxonMobil, whose chief executive Rex Tillerson called the idea of ethanol as a biofuel "moonshine" in 2007, last week announced a US\$600-million research alliance to develop biofuels from photosynthetic algae.

The multi-year project sees Exxon team up with Synthetic Genomics, the biotechnology company in La Jolla, California, co-founded by Craig Venter, which numbers another oil and gas giant, $\mathrm{BP}$, among its investors.

Synthetic Genomics will receive \$300 million - more, if deemed successful — to develop high-yielding algal strains and their large-scale cultivation. Exxon is spending an equal sum internally on engineering and manufacturing expertise to support the research.

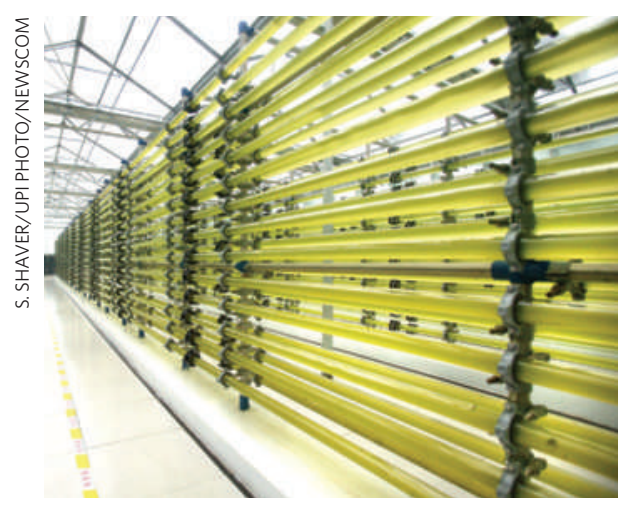

Green power: these tubes of algae are geared up to produce biofuel.

\title{
Jupiter takes a hit
}

An amateur astronomer has spotted the impact of an unknown object on Jupiter. The dark spot near Jupiter's southern pole (pictured, inset) was detected by Anthony Wesley of Murrumbateman, near Canberra, Australia, on 19 July. Shortly afterwards, word of the finding spread quickly via e-mails and the Internet.

Follow-up observations by the Keck infrared telescope (pictured) and by NASA's InfraRed Telescope Facility, both on Mauna Kea in Hawaii, rule out a storm, according to Glenn Orton, a planetary scientist at the Jet

Propulsion Laboratory in Pasadena, California. "This

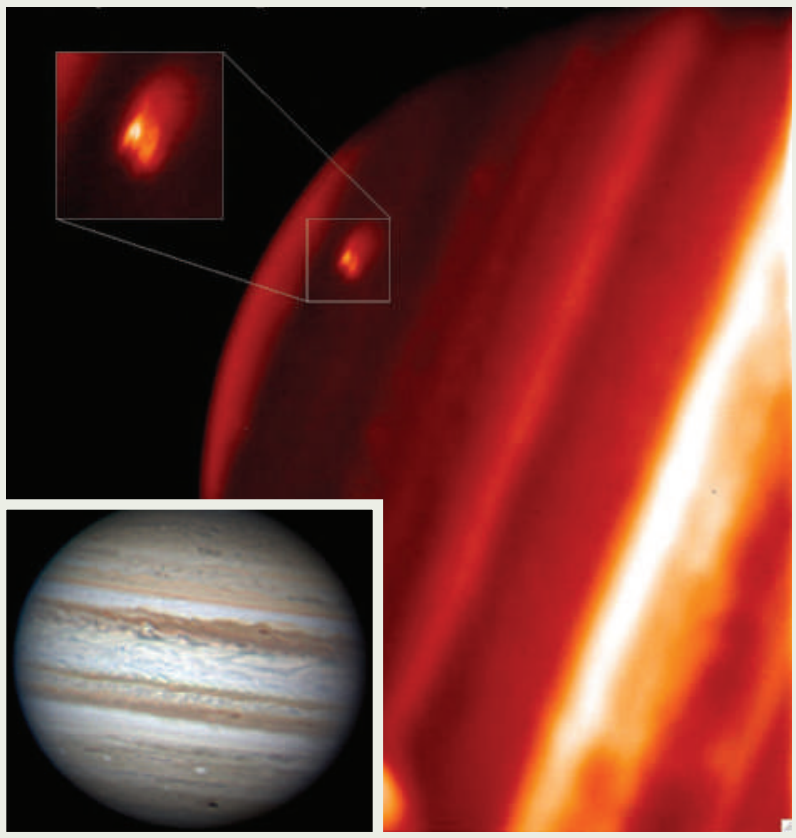
looks like nothing on Jupiter that is occurring naturally," Orton says.

The impact took place almost exactly 15 years after the first fragments of the comet Shoemaker-Levy 9 slammed into the giant planet.

\section{Italian court sidesteps stem-cell challenge}

An Italian court has informed scientists that they have no right to demand a halt to a call for research proposals that specifically excludes the use of human embryonic stem cells - even though their use is legal.

The researchers had objected when the exclusion was added by politicians to a text agreed by a committee of scientific experts (see Nature 460, 19; 2009). They argued that it contravenes a constitutional right to freedom of research.

The court said that only research institutes, not individuals, were eligible to object. The scientists are appealing against the decision in a higher court.

\section{Copernicus honoured in periodic-table addition}

The name of element 112 should be copernicium $(\mathrm{Cp})$, its discoverers proposed last week. Sigurd Hofmann's team at the GSI Helmholtz Centre for Heavy Ion Research in Darmstadt, Germany - who first created atoms of the element in 1996 - picked the name to honour astronomer Nicolaus Copernicus, famed for his heliocentric theory of the Solar System.

The superheavy element, previously known by the placeholder ununbium, was officially recognized by the International Union of Pure and Applied Chemistry (IUPAC) in May this year.

IUPAC confirmation of the new moniker awaits a six-month discussion period to iron out potential confusions. For instance, chemists already use $\mathrm{Cp}$ as shorthand for the cyclopentadienyl fragment $\mathrm{C}_{5} \mathrm{H}_{5}$.

\section{NOMINATE JAPAN'S BEST MENTORS}

The Nature Awards for Mentoring in Science are annual prizes that have been awarded by Nature since 2005 in recognition of excellence in the nurturing of young scientists.

The 2009 awards will be held in Japan, the first time that they have honoured mentors from an Asian nation. Nominations are invited for outstanding mentors from any scientific discipline based in Japan, in two categories: mid-career (up to 59 years of age) and lifetime achievement ( 60 years of age and over).

Nominations can come from current or former students or colleagues of the nominee from anywhere in the world, and must be supported by two additional people mentored at different times during the nominee's career. The awards, worth $¥ 1.5$ million (US $\$ 16,000$ ) each, will be presented in December 2009 at a ceremony at the UK ambassador's residence in Tokyo.

Nominations opened on 22 July, and will close on 25 September 2009. Applications may be made in either Japanese or English. Further details and nomination forms are available for download from www.natureasia.com/en/mentor (English) or www.natureasia.com/japan/mentor (Japanese). 